\title{
O ordenamento territorial no Brasil e os zoneamentos ecológicos econômicos dos estados
}

Nos últimos anos, o ordenamento territorial tem sido um tema muito discutido como ferramenta de política pública de gestão, mas pensar formas de organização do espaço não é algo recente. Desde o início do século XX vários países europeus começaram a estruturar a organização do espaço. Na América Latina, o ordenamento tem sido um dos instrumentos mais utilizados para intervir na organização e gestão do território, em particular, através de políticas e planos de uso do solo. No Brasil, após um longo período de eclipse, o debate sobre concepções e estratégias de ordenamento territorial e de desenvolvimento regional retornaram, no início deste novo milênio, à pauta da agenda política nacional. Nesse contexto, o Zoneamento Ecológico Econômico (ZEE) apareceu como um instrumento potencialmente poderoso de efetivação da gestão territorial. Ele foi estabelecido, por meio da Política Nacional de Meio Ambiente (Lei $n^{\circ}$ 6.938/1981), e regulamentado, anos mais tarde, pelo Decreto Federal no $4.297 / 2002$. Contudo, este artigo tem por objetivo apresentar a base legal do ZEE e discutir as políticas públicas de ordenamento ambiental do território, além de apresentar o cenário atual de elaboração e implementação dos Zoneamentos Ecológicos Econômicos no Brasil, identificando as iniciativas estaduais. Os dados apontam que os maiores gargalos dos estados são a regulamentação e a implementação de seus ZEEs. Aliar os estudos técnicos de zoneamento, como: diagnósticos, prognósticos, cenários, mapeamentos e diretrizes, aos interesses dos diversos atores institucionais e políticos que fazem uso e ocupação daquele espaço, visando contribuir com o ordenamento territorial ambiental, parece ser sempre o maior desafio para os estados. Nota-se ainda, que para a efetiva implementação deste instrumento deve haver um processo de construção coletiva, participativa, política e técnica de forma intensa e equitativa. Espera-se, que os Zoneamentos Ecológicos Econômicos estaduais como instrumento de organização do território, depois de elaborados e implementados, tenham um potencial para influir no ordenamento territorial e ambiental, via orientações, restrições e alternativas de uso e ocupação. $E_{\text {, }}$ portanto, influenciar a tomada de decisão sobre áreas distintas daquele espaço.

\section{The territorial planning in Brazil and the ecological economic zoning of the states}

\begin{abstract}
In recent years, territorial planning has been a widely discussed topic as a tool for public management policy, but thinking about ways of organizing space is not something recent. Since the beginning of the 20th a intervene in the organization and management of the territory, in particular, through land use policies and plans. In Brazil, after a long period of eclipse, the debate on conceptions and intervene in the organization and management of the territory, in particular, through land use policies and plans. In Brazil, after a long period of eclipse, the debate on conceptions and
strategies for territorial organization and regional development returned, at the beginning of this new millennium, to the agenda of the national political agenda. In this context, the Ecological strategies for territorial organization and regional development returned, at the beginning of this new millennium, to the agenda of the national political agenda. In this context, the Ecological
Economic Zoning (EEZ) appeared as a potentially powerful instrument for effecting territorial management. It was established through the National Environment Policy (Law No. 6.938/1981) and regulated, years later, by Federal Decree No. 4.297/2002. However, this article aims at presenting the legal basis of the EEZ and discussing the public policies for the environmental ordering of the territory, in addition to presenting the current scenario of elaboration and implementation of Ecological Economic Zoning in Brazil, identifying state initiatives. The data shows that the biggest bottlenecks in the states are the regulation and implementation of their EEZs. Combining technical zoning studies, such as: diagnostics, prognoses, scenarios, mappings and guidelines, with the interests of the various institutional and political actors that use and occupy that space, aiming at contributing to the environmental territorial ordering, always seems to be the greatest challenge for the states. It should also be noted that for the effective implementation of this instrument, there must be a collective, participatory, political and technical construction process in an in has a potential to influence territorial and environmental pring other than that space.
\end{abstract}

Keywords: Territorial Planning; Environmental planning; Ecological Economic Zoning.

Topic: Engenharia Ambiental

Reviewed anonymously in the process of blind peer.
Received: 03/06/2021

Approved: 27/06/2021
Rodrigo Araujo Fontes (iD)

Universidade do Estado do Rio de Janeiro, Brasil

http://lattes.cnpq.br/0458946381972402

http://orcid.org/0000-0001-5890-3171

rodrigoaf.ambiente@gmail.com

Elmo Rodrigues da Silva (id

Universidade do Estado do Rio de Janeiro, Brasil

http://lattes.cnpq.br/7790643519325582

http://orcid.org/0000-0002-1214-3151

elmo@eng.uerj.br
Referencing this:

FONTES, R. A.; SILVA, E. R.. O ordenamento territorial no brasil e os zoneamentos ecológicos econômicos dos estados. Revista lbero Americana de Ciências Ambientais, v.12, n.6, p.334-346, 2021. DOI: http://doi.org/10.6008/CBPC2179-6858.2021.006.0028 


\section{INTRODUÇÃO}

Nos últimos anos, o ordenamento territorial tem sido um tema muito discutido como ferramenta de política pública de gestão, especialmente no âmbito do planejamento regional, mas pensar formas de organização do espaço não é algo recente. Albrechts (2004) afirma que desde o início do século XX vários países europeus começaram a estruturar a organização do espaço, influenciados, principalmente, pelo acelerado crescimento populacional notado nas cidades. O ordenamento territorial teve seu início claramente com o foco na escala municipal, sendo, sobretudo, em leis específicas de regulamentação de uso do solo, sem leituras contextuais do espaço.

Na Europa, o conteúdo teórico e prático do ordenamento territorial se desenvolveu, especialmente, após as décadas de 1970 e 1980, com o surgimento do conceito de território como objeto estratégico de análise. Foi na década de 1980, que a Carta Europeia do Ordenamento do Território trouxe a visão espacial das políticas econômicas, sociais, culturais e ecológicas. Segundo Ferrão (2011), o ordenamento territorial na concepção atual possui caráter interdisciplinar, prospectivo e que se volta à utilização ótima do espaço.

Na América Latina, o ordenamento tem sido um dos instrumentos mais utilizados para intervir na organização e gestão do território, em particular, através de políticas e planos de uso do solo. Estas políticas se tornaram mais robustas nos anos 1980, acompanhando a evolução internacional da discussão sobre sustentabilidade e rebatimentos no pensamento integrado homem-espaço. O ordenamento territorial somente ganhou força na região como instrumento de planejamento e articulação intersetorial, a partir da visão sistêmica do espaço que se intensificou no início do Século XXI (RIO DE JANEIRO, 2015).

O Estado Desenvolvimentista Brasileiro, de corte cepalino, implementou, a partir dos anos 1940, um núcleo de consenso desenvolvimentista análogo ao keynesianismo europeu. Com viés explicitamente geopolítico no pós-64, o Estado autoritário brasileiro enfrentou, a partir dos anos 1980, o esvaziamento de suas propostas e viabilidades com a crise do Estado Desenvolvimentista (RÜCKERT, 2005). A concepção de ordenamento existente, até então, remontava à geografia regional francesa da década de 1960, que buscava utilizar o arsenal teórico e técnico desenvolvido para a análise regional em programas de planejamento estatal, tendo como objetivo a articulação das diferentes políticas públicas numa base territorial entendida como uma região-piloto (MORAES, 2005).

Peres et al. (2012) relatam que após um longo período de eclipse, o debate sobre concepções e estratégias de ordenamento territorial e de desenvolvimento regional retornaram, neste novo milênio, à pauta da agenda política brasileira. Depois de duas décadas - 1980 e 1990 - em que se predominou o pensamento macroeconômico, a questão da territorialidade nas estratégias de desenvolvimento vem retomando seu lugar na agenda política brasileira.

Nesse contexto, o Zoneamento Ecológico Econômico (ZEE) apareceu como um instrumento poderoso de efetivação da gestão territorial à medida que, ao constituir-se num instrumento técnico, de conhecimento acurado da realidade territorial e político de mediação entre diferentes territorialidades, permite o planejamento das diferenças, capaz de compatibilizar, de forma pactuada, o desenvolvimento econômico 
com a sustentabilidade ambiental, alterando o ambiente institucional das regiões onde opera (FIGUEIREDO, 2005).

Foi a partir da segunda metade dos anos 1980, que o debate sobre o planejamento territorial passou a incorporar elementos do discurso ambiental, fazendo com que ganhasse força a remissão a uma racionalidade ecológica, apresentada como necessária ao ordenamento territorial (ACSELRAD, 2000).

Assim, o Zoneamento Ambiental foi estabelecido, por meio da Política Nacional de Meio Ambiente (Lei no 6.938/1981), em seu artigo 9o, inciso II, como um de seus instrumentos. Anos mais tarde, o Decreto Federal no 4.297/2002, o regulamentou como Zoneamento Ecológico Econômico (ZEE), trazendo sua definição legal e seus objetivos:

Art. 2o O ZEE, instrumento de organização do território a ser obrigatoriamente seguido na implantação de planos, obras e atividades públicas e privadas, estabelece medidas e padrões de proteção ambiental destinados a assegurar a qualidade ambiental, dos recursos hídricos e do solo e a conservação da biodiversidade, garantindo o desenvolvimento sustentável e a melhoria das condições de vida da população.

Art. 3o O ZEE tem por objetivo geral organizar, de forma vinculada, as decisões dos agentes públicos e privados quanto a planos, programas, projetos e atividades que, direta ou indiretamente, utilizem recursos naturais, assegurando a plena manutenção do capital e dos serviços ambientais dos ecossistemas.

Parágrafo único. O ZEE, na distribuição espacial das atividades econômicas, levará em conta a importância ecológica, as limitações e as fragilidades dos ecossistemas, estabelecendo vedações, restrições e alternativas de exploração do território e determinando, quando for o caso, inclusive a relocalização de atividades incompatíveis com suas diretrizes gerais.

Segundo Becker et al. (1996), a proposição desse instrumento respondia a um novo contexto. Em nível nacional tratava-se do esgotamento do modelo desenvolvimentista caracterizado por forte atuação governamental centralizada e da retomada do planejamento em novas bases. Para os autores, a gestão do território tem entre suas maiores funções o zoneamento, o monitoramento dos efeitos do desenvolvimento, os problemas da degradação ambiental e o fortalecimento das normas embutidas na legislação. E o zoneamento é seu instrumento mais importante.

Dessa forma, este instrumento de organização do território, em nível estadual, passou a ser obrigatoriamente seguido na implantação de planos, obras e atividades públicas e privadas, com o dever de estabelecer medidas e padrões de proteção ambiental destinados a assegurar a qualidade ambiental, dos recursos hídricos e do solo e a conservação da biodiversidade, garantindo o desenvolvimento sustentável e a melhoria das condições de vida da população. Sendo seu objetivo geral, organizar, de forma vinculada, as decisões dos agentes públicos e privados quanto a planos, programas, projetos e atividades que, direta ou indiretamente, utilizem recursos naturais, assegurando a plena manutenção do capital e dos serviços ambientais dos ecossistemas.

Nesse sentido, este artigo tem por objetivo apresentar a base legal do ZEE, o cenário atual de elaboração e implementação dos Zoneamentos Ecológicos Econômicos no Brasil, identificando as iniciativas estaduais e discutir as políticas públicas de ordenamento ambiental do território. 


\section{METODOLOGIA}

Para a operacionalização da pesquisa e o atendimento aos objetivos, fez-se necessária uma vasta revisão de literatura procurando estabelecer uma fundamentação teórica e discutir conceitos e categorias como: território, políticas territoriais e ordenamento territorial, planejamento ambiental e a questão ambiental. Além disso, um levantamento bibliográfico dos documentos que regem as políticas públicas referentes ao ZEE e ao ordenamento territorial como: planos, legislações e programas governamentais.

Estes conceitos e categorias norteiam a pesquisa e tem por base os estudos dos seguintes autores: Território e Políticas territoriais, propostos por Costa (1988), Raffestin (1993) e Souza (2000); Ordenamento Territorial e (re)organização do espaço, conforme Gaspar (1995), Becker et al. (1996) e Moraes (2005); Planejamento Ambiental e a Questão Ambiental, segundo Acselrad (2000), e Rodriguez et al. (2013). Estabelecer este arcabouço teórico foi de importância fundamental, pois permite a compreensão e a análise das discussões aqui propostas.

Outro ponto foi o levantamento de dados secundários referentes à dimensão territorial do planejamento. Dados disponibilizados pelo Ministério do Meio Ambiente por meio da sua área de gestão territorial, pelas secretarias estaduais, através das coordenações dos ZEEs dos estados, pelas empresas de consultoria que prestam serviços aos governos estaduais, além de trabalhos científicos que tratam do tema.

Com isso, foi realizado o cruzamento de informações referentes a legislação vigente, como o artigo 225 da Constituição Federal de 1988 (BRASIL, 1988), a Lei Federal n.ㅇ 6.938 (BRASIL, 1981) que estabelece a Política Nacional de Meio Ambiente, o Decreto Federal n.o 4.297 (BRASIL, 2002) que regulamenta o ZEE, as normativas e atas da Comissão Nacional do ZEE, o documento "Diretrizes metodológicas para o Zoneamento Ecológico Econômico no Brasil” que teve sua terceira edição editada em 2006, com as normatizações estaduais, relatórios (produtos) dos ZEEs dos estados e os procedimentos de elaboração e implementação atuais. E para auxiliar a interpretação e análise dos dados, foram elaboradas figuras e tabelas.

\section{RESULTADOS}

\section{Arcabouço Legal do Zoneamento Ecológico Econômico no Brasil}

Estabelece-se aqui um arcabouço legal e histórico do ZEE no Brasil, tendo a regulamentação federal como eixo norteador, o zoneamento ambiental como objeto e o período após a Política Nacional do Meio Ambiente como foco.

O ordenamento territorial, as políticas de planejamento e o zoneamento, são objeto de antigas discussões e textos legais. Não obstante já existir há décadas, ainda hoje se verifica em nosso país a ausência de um programa nacional de ordenamento territorial, carência em políticas públicas de planejamento ambiental e ações públicas bem definidas para implementação de zoneamentos. O que faz refletir na prática em crescimento desordenado e suas consequências socioambientais nos territórios.

Apesar de não existirem fases bem definidas para a evolução normativa para o zoneamento, verificase que desde a década de 1960 se tem registros de citação ao termo. Como por exemplo na lei 4.504 de 1964, 
conhecida como Estatuto da Terra, que cria o zoneamento agrário, e em seu artigo 5o trata de zonas ecológico-econômicas, estabelecendo o então Instituto Brasileiro de Reforma Agrária (IBRA), como responsável por realizar o zoneamento das áreas prioritárias. Ainda na década de 1960, outras normatizações criadas estão relacionadas ao tema, como: a Lei 4.771 de 1965, que instituiu o código florestal; a Lei 5.173, que dispõe sobre o plano de valorização econômica da Amazônia; e o plano nacional e planos regionais de desenvolvimento em 1967.

A década de 1970 é marcada por debates internacionais sobre o meio ambiente, sobretudo, a conferência nas nações unidas sobre o meio ambiente, realizada em 1972, em Estocolmo. O evento e suas discussões, se tornaram referência para o debate internacional das questões ambientais, dentre elas, a integração de aspectos naturais e sociais na gestão territorial. Contudo, se intensificou a preocupação interna com o meio ambiente e assim a legislação em torno do tema. Foi nesta década que tivemos a criação do Estatuto do Índio, reafirmando o direito a posse das terras que habitam às comunidades indígenas e ao usufruto exclusivo das riquezas naturais. E ainda, o estabelecimento das regiões metropolitanas, a aprovação do segundo plano de nacional de desenvolvimento, a regulamentação da política agrícola e da reforma agrária, até chegarmos em novas normativas que estabeleciam suas formas de zoneamento, como: o Decreto-Lei 1.413 que trata das áreas críticas de poluição industrial e estabelece que o zoneamento urbano deve viabilizar alternativas locacionais para indústrias poluentes; a lei 6.513 de 1977 que ficou conhecida como zoneamento turístico; até chegarmos em 1979 quando o grupo de trabalho criado pelo presidente da república, através do Decreto 83.518, para estudar e propor uma política florestal para Amazônia brasileira, concluiu dentre outros elementos, a necessidade de realização do ZEE, abordando unidades de conservação e áreas para colonização e regulação fundiária; outro decreto, o de no 84.017 regulamenta o artigo 5o no então código florestal (Lei 4.771/65) e cria a figura do zoneamento nos planos de manejo dos parques nacionais.

A década de 1980 é a de maior destaque quanto a regulamentação ambiental no Brasil. É neste período em que surgiu a constituição federal vigente, a qual possui um capítulo dedicado ao meio ambiente, e a política nacional de meio ambiente. A Política Nacional do Meio Ambiente (Lei Federal no 6.938/1981), instituída com o objetivo de preservar, melhorar e recuperar a qualidade ambiental, estabeleceu, entre seus instrumentos de execução, o zoneamento ambiental. Posteriormente, ele foi regulamentado sob a denominação de Zoneamento Ecológico-Econômico (ZEE) e também foi previsto no Plano Nacional de Gerenciamento Costeiro (Lei Federal no 7.661/1988) como instrumento de gestão da zona costeira.

Ainda nos anos de 1980, o Decreto no 96.944/1988, criou o Programa de Defesa do Complexo de Ecossistemas da Amazônia Legal, denominado "Programa Nossa Natureza", com a finalidade de estabelecer condições para a utilização e a preservação do meio ambiente e dos recursos naturais renováveis na Amazônia Legal, mediante a concentração de esforços de todos os órgãos governamentais e a cooperação dos demais segmentos da sociedade com atuação na preservação do meio ambiente. Um de seus objetivos era disciplinar a ocupação e exploração racionais fundamentadas no ordenamento territorial.

Em 1990, o decreto federal no 99.193/1990, dispõe sobre as atividades relacionadas ao ZEE e instituí 
um grupo de trabalho com o encargo de conhecer e analisar os trabalhos de ZEE existentes, propondo, no prazo de noventa dias, as medidas necessárias para agilizar sua execução, com prioridade para a Amazônia Legal. Uma das maiores contribuições deste grupo de trabalho foi a recomendação para a criação de uma Comissão Coordenadora com o objetivo de orientar a execução do ZEE no território nacional - CCZEE. A CCZEE foi então criada pelo decreto federal no 99.540/1990, tendo a secretaria de assuntos estratégicos da presidência da república (SAE) como braço executivo na coordenação.

Em 1991, por meio da CCZEE e da SAE, foi criado o Programa de Zoneamento para a Amazônia Legal (PZEEAL). Todos os estados da Amazônia criaram Comissões Estaduais de ZEE e firmaram convênios com o governo federal, que descentralizou recursos para a implantação de laboratórios de geoprocessamento. 0 Instituto Nacional de Pesquisas Espaciais (Inpe) ficou responsável por treinar equipes de ZEE dos estados da Amazônia, capacitando os técnicos dos estados entre os anos de 1994 e 1995.

Experiências isoladas de zoneamento eram iniciadas por outros órgãos federais. O Programa Nacional de Gerenciamento Costeiro, que desde o início da década de 1980 desenvolvia propostas de zoneamento na área costeira, estabeleceu uma metodologia de zoneamento, posteriormente revisada, adaptada e consolidada. Em meados da década de 1990, foi elaborado um Macrodiagnóstico da Zona Costeira na Escala da União, cuja revisão foi concluída em 2008, dando origem ao Macrodiagnóstico da Zona Costeira e Marinha do Brasil.

Em 1995, a SAE atentou para a necessidade de definir mais claramente os procedimentos para elaboração do ZEE. Essa necessidade foi despertada pelos zoneamentos já em processo de execução na Amazônia Legal. Em parceria com a Secretaria de Coordenação da Amazônia do Ministério do Meio Ambiente, foram solicitadas, por meio de convite, propostas de metodologia de zoneamento a diversos especialistas. Foi eleita a proposta do Laboratório de Gestão Territorial da Universidade Federal do Rio de Janeiro (LAGET/UFRJ), posta em debate e publicada, no documento "Detalhamento da Metodologia para Execução do Zoneamento Ecológico-Econômico pelos Estados da Amazônia Legal”.

Becker et al. (1996) estabeleceram o conceito de zonas ecológico-econômicas: 1 - ecológica, que reflete as limitações e potencialidades do uso sustentável dos recursos naturais; 2 - econômica, que manifesta as aspirações de desenvolvimento humano da sociedade. A definição veio a partir da concepção de unidades ecodinâmicas propostas por Tricart (1977), que define os ambientes como estáveis; instáveis; e fortemente instáveis (Vulnerabilidade do território).

Ao fim dos anos 1990, a responsabilidade pela ordenação territorial foi transferida para o Ministério da Integração Nacional, enquanto ao Ministério do Meio Ambiente foi atribuída a responsabilidade pelo ZEE, o que provocou mudança de rumos na realização dos ZEEs. Essa atribuição foi confirmada posteriormente, pela lei federal $n^{\circ} 10.683 / 2003$, tendo sido mantida por intermédio da lei federal $n$ ㅇ 13.341/2016

A primeira década deste século, destacou-se pelo processo nacional de discussão sobre o ZEE. Após a criação do Programa Zoneamento Ecológico-Econômico e sua inclusão no plano plurianual do ciclo 20002003, foram realizados seminários nacionais e regionais com a participação de representantes das esferas estatais, pesquisadores e sociedade civil organizada. E estes atores puderam debater e trocar experiências a 
respeito deste instrumento. Com base nestas discussões, foi possível consolidar uma metodologia para a organização do Programa e articular procedimentos operacionais de zoneamento. Os resultados aparecem no documento "Diretrizes Metodológicas para o ZEE do Território Nacional" (BRASIL, 2001). O documento, que teve sua a última atualização realizada em 2006, consolida e sistematiza as discussões regionais sobre a metodologia de ZEE, define diretrizes metodológicas e procedimentos operacionais mínimos para a execução e implementação do ZEE nos níveis táticos e estratégicos, formalizando os requisitos necessários à execução de projetos de ZEE.

Junto a esse esforço foi restabelecida a CCZEE e criado um consórcio de empresas públicas, denominado de Consórcio ZEE Brasil, regulamentado por meio do decreto federal s/no de 28/12/2001. Por fim, o poder executivo federal estabeleceu o decreto $n$ n 4.297/2002, regulamentando o processo de implementação do ZEE em território nacional, como instrumento da Política Nacional do Meio Ambiente e estabelecendo os objetivos, as diretrizes, os produtos e as condições para execução de projetos em conformidade com as diretrizes metodológicas.

\section{O Zoneamento Ecológico Econômico no Brasil: Princípios e Diretrizes}

Segundo o Ministério do Meio Ambiente (BRASIL, 2011), o ZEE é um instrumento para planejar e ordenar o território brasileiro, harmonizando as relações econômicas, sociais e ambientais que nele acontecem. Demanda um efetivo esforço de compartilhamento institucional, voltado para a integração das ações e políticas públicas territoriais, bem como articulação com a sociedade civil, congregando seus interesses em torno de um pacto pela gestão do território. O órgão estabelece ainda o ZEE como ponto central na discussão das questões fundamentais para o futuro do Brasil como, por exemplo, a questão da Amazônia, do cerrado, do semiárido brasileiro, dos biocombustíveis e das mudanças climáticas.

Para tal, o MMA (BRASIL, 2011) aponta princípios norteadores devendo o instrumento ser: participativo, equitativo, sustentável, holístico e sistêmico. Participativo no qual os atores sociais devem intervir durante as diversas fases dos trabalhos, desde a concepção até a gestão, com vistas à construção de seus interesses próprios e coletivos. Para que o ZEE seja autêntico, legítimo e realizável; Equitativo promovendo a Igualdade de oportunidade de desenvolvimento para todos os grupos sociais e para as diferentes regiões; Sustentável onde o uso dos recursos naturais e do meio ambiente deve ser equilibrado, buscando a satisfação das necessidades presentes sem comprometer os recursos para as próximas gerações; Holístico com uma abordagem interdisciplinar para a integração de fatores e processos, considerando a estrutura e a dinâmica ambiental e econômica, bem como os fatores histórico-evolutivos do patrimônio biológico e natural; e Sistêmico de maneira que propicie a análise de causa e efeito, permitindo estabelecer as relações de interdependência entre os subsistemas físico-biótico e socioeconômico.

Pelas diretrizes estabelecidas pelo Ministério do Meio Ambiente (BRASIL, 2006), o ZEE pode ser dividido em quatro etapas principais: planejamento, diagnóstico, prognóstico e subsídios para implementação, conforme apresentado na Figura 1.

De forma geral, o planejamento é onde devem ser definidos os objetivos e horizontes do ZEE. O 
diagnóstico é o levantamento físico-biótico, socioeconômico e jurídico institucional do território. O prognóstico é onde define-se áreas de intervenção e a formulação de cenários a partir das condições naturais, sociais e econômicas em conjunto com contexto regional, nacional e global. E os subsídios para implementação se baseia nas relações institucionais definidas anteriormente na fase de planejamento em que o corpo executor deve dar apoio técnico aos formuladores de políticas públicas para que as políticas e a gestão do território decorram dos cenários propostos pelo ZEE.

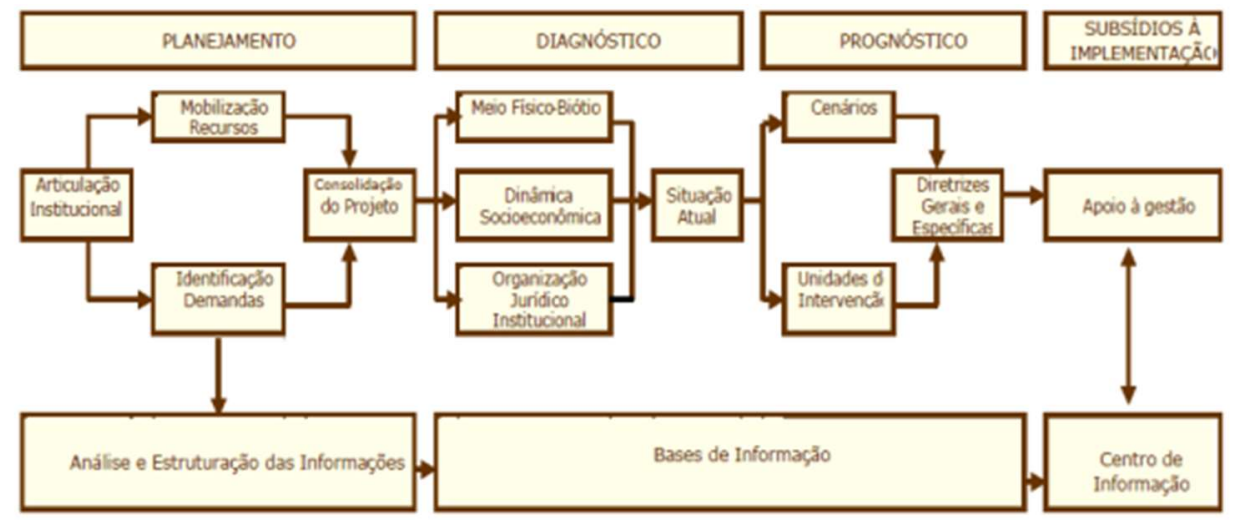

Figura 1: Fluxograma com as principais atividades do ZEE e suas articulações. Fonte: Diretrizes Metodológicas - BRASIL (2006).

Os ZEEs geram produtos e informações em escalas que variam de acordo com o tamanho da área estudada, o tipo de detalhe que se pretende obter, e com a disponibilidade de informações da sua área de abrangência. Segundo o Decreto $n^{\circ} 4.297$ (BRASIL, 2002), as escalas do Sistema Nacional de ZEEs são: Nacional - 1:5.000.000 (um para cinco milhões); Macrorregionais - 1:1.000.000 (um para um milhão); Estaduais - 1:1.000.000 a 1:3.000.000, 1:250.000 e 1:100.000; Locais - a partir de 1:100.000 (um para cem mil) em escala de detalhe, nos ZEEs realizados nos municípios e em Unidades de Conservação.

\section{O Cenário Atual do Zoneamento Ecológico Econômico Estaduais no Brasil}

Entre as iniciativas de zoneamentos ecológicos econômicos no Brasil temos aquelas em escala regional, organizadas e coordenadas pela esfera federal, a exemplo dos ZEEs do Baixo Rio Paranaíba de 2002, da Amazônia Legal de 2010 e da Bacia Hidrográfica do Rio São Francisco de 2018. Outros são setoriais ou locais como ZEE da Caatinga e das Serras Úmidas do Estado do Ceará, o ZEE do Núcleo Metropolitano de Recife, além dos chamados ZEECs que são os Zoneamentos Ecológicos Econômicos da Zona Costeira. Neste estudo abordarmos os ZEEs estaduais, que são aqueles que compreendem a totalidade do território dos estados e foram coordenados por esta esfera de governo.

Estabelecemos então a situação atual do ZEE no Brasil no que se refere as iniciativas estaduais. Para tal dividimos os estados pelas macrorregiões brasileiras e o instrumento em suas diferentes fases: Planejamento, Diagnóstico, Prognóstico e Proposta de Gestão. Foram elencados também quais estados possuem normatização para elaboração e/ou implementação dos seus zoneamentos e quais estados possuem a validação da comissão nacional do ZEE para seus estudos. Para os estados que já finalizaram seus ZEEs é apresentado seu ano de conclusão. 
A tabela 1 destaca os elementos concluídos para cada ZEE estadual. Notamos que somente os estados do Acre e de Rondônia possuem todas as fases concluídas, incluindo sua normatização e validação federal. Treze estados da federação concluíram as quatros fases (Planejamento, Diagnóstico, Prognóstico e Proposta de Gestão) do seu ZEE. Sendo cinco da região norte: Acre, Amazonas, Pará, Rondônia, Tocantins. Dois da região nordeste: Maranhão e Piauí. Dois na região centro-oeste: Mato Grosso e Distrito Federal. Dois na região sudeste: Minas Gerais e Rio de Janeiro. E dois na região sul: Paraná e Rio Grande do Sul.

Tabela 1: Situação dos ZEEs Estaduais no Brasil.

\begin{tabular}{|c|c|c|c|c|c|c|c|}
\hline \multicolumn{8}{|c|}{ Situação do ZEE no Brasil } \\
\hline \multicolumn{8}{|c|}{ Iniciativas Estaduais } \\
\hline Região / Estado & Planejamento & Diagnóstico & Prognóstico & Proposta de Gestão & Normatização & Ano de Conclusão & Validação \\
\hline \multicolumn{8}{|l|}{ Região Norte } \\
\hline Acre & concluído & concluído & concluído & concluído & sim (lei estadual no 1.904, de 05 de junho de 2007 & 2007 & $\operatorname{sim}$ \\
\hline Amapá & em andamento & não iniciado & não iniciado & não iniciado & não & $\mathrm{xxx}$ & não \\
\hline Amazonas & concluído & concluído & concluído & concluído & sim (lei estadual no 3.417 , de 31 de julho de 2009 & 2009 & $\operatorname{sim}$ \\
\hline Pará & concluído & concluído & concluído & concluído & sim (lei estadual no 6.745 , de 06 de maio de 2005 & 2005 & $\operatorname{sim}$ \\
\hline Rondônia & concluído & concluído & concluído & concluído & $\begin{array}{c}\text { sim (lei complementar estadual no } 233 \text {, de } 06 \text { de junho de 2000, retificada pela } \\
\text { lei complementar estadual no } 312 \text {, de } 06 \text { de maio de 2005) }\end{array}$ & 2005 & $\operatorname{sim}$ \\
\hline Roraima & concluído & em revisão & em revisão & em revisão & $\begin{array}{c}\text { sim (lei complementar estadual no 143, de } 15 \text { de janeiro de 2009, retificada } \\
\text { pela lei complementar estadual no 144, de } 06 \text { de março de 2009) }\end{array}$ & $\mathrm{xxx}$ & não \\
\hline Tocantins & concluído & concluído & concluído & concluído & não & 2018 & não \\
\hline \multicolumn{8}{|l|}{ Região Nordeste } \\
\hline \multicolumn{8}{|l|}{ Alagoas } \\
\hline Bahia & concluído & concluído & concluído & em andamento & não & $\mathrm{xxx}$ & não \\
\hline \multicolumn{8}{|l|}{ Ceará } \\
\hline Maranhão & concluído & concluído & concluído & concluido & sim (lei estadual no 10.316, de 17 de setembro de 2015 & $\mathrm{xxx}$ & não \\
\hline \multicolumn{8}{|l|}{ Paraiba } \\
\hline \multicolumn{8}{|l|}{ Pernambuco } \\
\hline Piauí & concluído & concluído & concluído & concluído & não & 2014 & não \\
\hline \multicolumn{8}{|l|}{ Rio Grande do Norte } \\
\hline Sergipe & concluído & não iniciado & não iniciado & não iniciado & não & $\mathrm{xxx}$ & não \\
\hline \multicolumn{8}{|l|}{ Região Centro-Oeste } \\
\hline Goiás & concluído & em andamento & não iniciado & não iniciado & não & $\mathrm{xxx}$ & não \\
\hline Mato Grosso & concluído & concluído & concluído & concluído & sim (lei estadual no 9.523, de 20 de abril de 2011) - Suspensão Judicial & $\mathrm{xxx}$ & não \\
\hline Mato Grosso do Sul & concluído & concluído & em andamento & não iniciado & não & $x x x$ & não \\
\hline Distrito Federal & concluído & concluído & concluído & concluído & sim (lei distratal no 1988/2018) & 2018 & não \\
\hline \multicolumn{8}{|l|}{ Região Sudeste } \\
\hline Espírito Santo & concluído & concluído & não elaborado & concluído & não & 2010 & não \\
\hline Minas Gerais & concluído & concluído & concluído & concluído & $\begin{array}{c}\text { sim (deliberação normativa no 129, de } 27 \text { de novembro de 2008, do Conselho } \\
\text { Estadual de Política Ambiental - Copam) }\end{array}$ & 2008 & não \\
\hline São Paulo & em andamento & em andamento & não iniciado & não iniciado & não & $\mathrm{xxx}$ & não \\
\hline Rio de Janeiro & concluído & concluído & concluído & concluído & não & 2018 & não \\
\hline \multicolumn{8}{|l|}{ Região Sul } \\
\hline Paraná & concluído & concluído & concluído & concluído & não & 2017 & não \\
\hline Rio Grande do Sul & concluído & concluído & concluído & concluído & não & 2018 & não \\
\hline Santa Catarina & & & & & & & \\
\hline
\end{tabular}

A partir de então é preciso fazer algumas ressalvas. A primeira delas é quanto a escala. Segundo o Decreto $n^{\circ} 4.297 / 2002$, o ZEE para fins de reconhecimento do poder público deverá gerar produtos e informações na escala de referência de 1:1.000.000 a 1:250.000, nas macrorregiões norte, centro-oeste e nordeste e de 1:250.000 a 1:100.000 nas macrorregiões sudeste, Sul e na zona costeira. Os estados do Amazonas e Pará, na região norte, e Maranhão e Piauí, na região nordeste concluíram o chamado Macro ZEE, pois compreendem a escala de 1:1.000.000. Nesta escala o ZEE tem como função indicativos estratégicos de uso do território, definição de áreas para detalhamento do ZEE, utilização como referência para definição de prioridades em planejamento territorial e gestão de ecossistemas. Já para escalas de 1:250.000 e maiores, serve para indicativos de gestão e ordenamento territorial estadual ou regional, tais como, definição dos percentuais para fins de recomposição ou aumento de reserva legal. Se for construído na escala de até 1:100.000, como no caso do ZEE do Rio de Janeiro, permite desempenhar funções operacionais de gestão e ordenamento territorial.

O estado do Mato Grosso traz uma segunda questão. Seu ZEE estadual foi profundamente alterado ao ser levado à discussão legislativa. Passando a não refletir mais as diretrizes metodológicas do MMA, por essa razão não obtendo a validação federal, e sendo suspenso por vias judiciais, levado a novos estudos e 
discussões no ano passado. A partir desses critérios deixamos de ter treze zoneamentos finalizados para termos somente oito. Outro ponto é que dos oitos estados que finalizaram seus ZEEs somente quatro criaram normatizações para a sua implementação são eles: Acre, Rondônia, Distrito Federal e Minas Gerais, o que leva a baixa institucionalização do conhecimento e aplicação dos dados, além de dificultar a constituição do aparato de planejamento ambiental e dos instrumentos de gestão do território.

Muitos estados iniciaram o processo de elaboração, findaram parte de suas fases, mas não concluíram. Outros tiveram apenas iniciativas setoriais ou locais e há ainda casos de estados que sequer constituíram a base de seus zoneamentos, como os estados de Alagoas, que não iniciou o planejamento do seu ZEE, e Sergipe que concluiu apenas a fase de planejamento.

Todo este cenário nos mostra que a elaboração dos ZEEs estaduais esteve em um primeiro momento fortemente ligada aos incentivos e discussões para o zoneamento da Amazônia legal. O que se deve notadamente aos próprias interesses institucionais em promover o ordenamento territorial e ambiental daquela região do país, contribuindo para elaboração de grande parte dos ZEEs dos estados da região norte, que se daria logo após a regulamentação do instrumento, na primeira década dos anos 2000.

Outro fator que impulsionou novas iniciativas em nível estadual na segunda década deste século, foi a promulgação da lei 12.651 de 2012, o chamado "novo" código florestal, que em seu artigo 13, § $2^{\circ}$ determinou o prazo de cinco anos para elaboração dos ZEEs estaduais para aqueles que ainda não o possuíam (BRASIL, 2012).

Por outro lado, os dados apontam que os maiores gargalos dos estados são a regulamentação e a implementação de seus ZEEs. Aliar os estudos técnicos de zoneamento, como: diagnósticos, prognósticos, cenários, mapeamentos e diretrizes, aos interesses dos diversos atores institucionais e políticos que fazem uso e ocupação daquele espaço, visando contribuir com o ordenamento territorial ambiental, parece ser sempre o maior desafio para os estados. Nota-se ainda, que para a efetiva implementação deste instrumento deve haver um processo de construção coletiva, participativa, política e técnica de forma intensa e equitativa.

\section{DISCUSSÃO}

\section{Ordenamento Territorial, Planejamento Ambiental e Zoneamento Ecológico Econômico}

Para discutir as políticas públicas de ordenamento ambiental do território e apresentar o cenário atual de elaboração e implementação dos Zoneamentos Ecológicos Econômicos no Brasil, se faz necessário, aprofundar os estudos dos conceitos e categorias que a todo tempo estão inseridos no processo de construção deste instrumento, e são palco de múltiplos debates entre os pesquisadores.

Um desses é o território, que para Raffestin (1993), um dos pioneiros na abordagem desse conceito, o território está vinculado a um caráter político e associa-se ao conceito de espaço, sendo posterior a esse. Para o autor, é essencial compreender bem que o espaço é anterior ao território. O território se forma a partir do espaço, e é o resultado de uma ação conduzida por um ator sintagmático (ator que realiza um programa) em qualquer nível. Ao se apropriar de um espaço, concreto ou abstratamente, o ator territorializa. 
Para Souza (2000), território são relações sociais projetadas no espaço, podendo ser entendido como espaços sociais, ou seja, relações de poder espacialmente delimitadas e operando sobre um substrato referencial, podendo formar-se e dissolver-se, constituir-se e dissipar-se, ser instáveis ou estáveis, ou ter existência apenas em alguns momentos. Como tal, quase sempre está associado a uma superposição de territórios, com formas variadas e limites que não coincidem, além de existir contradições entre diversas territorialidades, por conta dos atritos e contradições existentes entre os diversos poderes dos grupos sociais que nele atuam.

Outro ponto fundamental é compreender as políticas territoriais. Segundo Costa (1988), tais políticas extrapolam a noção dos planos regionais de desenvolvimento. Elas abrangem toda e qualquer atividade que implique, simultaneamente, uma dada concepção do espaço nacional; uma estratégia de intervenção ao nível da estrutura territorial bem como mecanismos concretos que sejam capazes de viabilizar estas políticas. Um destes mecanismos seriam os Zoneamentos Ecológicos Econômicos, que tem se constituído cada vez mais como um instrumento do governo brasileiro para tentar disciplinar o uso dos territórios (RODRIGUEZ et al., 2013).

Como o ZEE é considerado um instrumento das políticas territoriais para ordenar o território, faz-se necessário discutir cientificamente o ordenamento territorial e sua articulação com o planejamento ambiental.

Para Gaspar (1995), o ordenamento do território é a arte de adequar as gentes e a produção de riqueza ao território numa perspectiva de desenvolvimento. Para Moraes (2005):

O ordenamento territorial diz respeito a uma visão macro do espaço, enfocando grandes conjuntos espaciais (biomas, macrorregiões, redes de cidades, etc.) e espaços de interesse estratégico ou usos especiais (zona de fronteira, unidades de conservação, reservas indígenas, instalações militares, etc.). Trata-se de uma escala de planejamento que aborda o território nacional em sua integridade, atentando para a densidade da ocupação, as redes instaladas e os sistemas de engenharia existentes (de transporte, comunicações, energia, etc.). Interessam a ele as grandes aglomerações populacionais (com suas demandas e impactos) e os fundos territoriais (com suas potencialidades e vulnerabilidades), numa visão de contiguidade que se sobrepõe a qualquer manifestação pontual no território.

No campo do planejamento ambiental a visão sistêmica é fundamental, pois os sistemas ambientais são considerados como sendo originados por estruturas conexas, totais e sistêmicas, que são variáveis dinâmicas e que estão sujeitas a uma complexa rede de cadeias de causa-efeito submetida à retroalimentação (SOUZA, 2002). Para Acselrad (2000), a "racionalidade ecológica" aplicada ao planejamento territorial vem sendo objeto de construções discursivas distintas, que ganham pertinência analítica enquanto manifestações de dinâmicas sociais.

O Zoneamento veio constituir-se assim como uma dimensão territorial do que tem sido chamado de "modernização ecológica" - conjunto de políticas de minimização do risco ambiental pela caracterização de "vulnerabilidades", criação de arranjos institucionais e práticas regulatórias tendentes a imprimir temporalidade julgada apropriada - a desejada "sustentabilidade" - às formas de apropriação dos recursos territorializados (ACSELRAD, 2000). Assume-se que o ZEE é, justamente, um instrumento capaz de romper as posições polarizadas, oferecendo oportunidades de crescimento econômico e uso dos recursos naturais 
através da qualidade ambiental (BECKER et al., 1996).

Ao tratarmos os aspectos da elaboração dos ZEEs estaduais é necessário compreender que um duplo mecanismo de poder se liga à produção do ZEE. Um poder que se exerce sobre as práticas do zoneamento através das exigências externas das hierarquias políticas, e um poder que se exerce pelo saber cartográfico e classificatório, pelo modo como os zoneadores criam uma concepção do espaço, ou seja, um poder incorporado à própria retórica do ZEE (ACSELRAD, 2000).

Portanto, intervir no ordenamento do território dos estados, tal como o ZEE se propõe, por meio das suas zonas, significa atuar sobre uma unidade espacial complexa, marcada pela interação e sobreposição de diversos atores e esferas de competência, cujos interesses são convergentes e conflitantes. Nesse contexto, emerge a necessidade de buscar definições para o que se denominou chamar de conflitos socioambientais, mas de antemão, é importante frisar, conforme aponta Chaves et al. (2008), que a definição desse termo comporta grande complexidade. Mesmo contando com uma ampla literatura acerca da questão ambiental, a definição do que seja conflito socioambiental é em si mesmo um dilema, com usos diversos que assumem contornos complexos e mesmo antagônicos na literatura. Estudar os conflitos é, para os envolvidos na busca dos processos mais democráticos de ordenamento do território, dar visibilidade, no debate sobre a gestão das águas, dos solos, da biodiversidade e das infraestruturas urbanas, aos distintos atores sociais que resistem aos processos de monopolização dos recursos ambientais nas mãos dos grandes interesses econômicos (ACSELRAD, 2004). Assim verificar e avaliar os conflitos existentes nestas instâncias e as possibilidades do sucesso operacional deste instrumento chamado ZEE é um dos aspectos fundamentais na busca para a gestão sustentável do território.

\section{CONCLUSÕES}

Intervir no ordenamento dos territórios dos estados, tal como o ZEE se propõe, por meio das suas zonas, significa atuar sobre uma unidade espacial complexa, marcada pela interação e sobreposição de diversos atores e esferas de competência, cujos interesses são convergentes e conflitantes (RIO DE JANEIRO, 2015).

O baixo número de zoneamentos em nível estadual chama a atenção, tendo em vista, a determinação, contida na Lei Federal 12.651/2012, para que sua elaboração e aprovação fosse realizada até o ano de 2017. Mas, sobretudo, destaca-se negativamente o fato de termos somente dois estados da federação com todas as fases técnicas concluídas, sua normatização e a validação federal. Tais fatos, nos permitem concluir, que há uma baixíssima implementação de fato deste instrumento em seus estados.

Ressalta-se, que mesmo depois de implantada, esta política territorial deve ter mecanismos de avaliação e monitoramento eficientes para corrigir possíveis distorções e buscar continuamente o aperfeiçoamento dos ZEEs, em virtude da sua alta complexidade política, social, econômica e ambiental.

Contudo, espera-se, que os Zoneamentos Ecológicos Econômicos estaduais como instrumento de organização do território, depois de elaborados e implementados, tenham um potencial para influir no ordenamento territorial e ambiental, via orientações, restrições e alternativas de uso e ocupação. E, 
portanto, influenciar a tomada de decisão sobre áreas distintas daquele espaço.

AGRADECIMENTOS: O presente trabalho foi realizado com apoio da Coordenação de Aperfeiçoamento de Pessoal de Nível Superior - Brasil (CAPES) - Código de Financiamento 001.

\section{REFERÊNCIAS}

ACSELRAD, H.. Zoneamento Ecológico-Econômico: entre ordem visual e mercado-mundo. In: ENCONTRO NACIONAL DE ESTUDOS POPULACIONAIS, 12. Anais. Caxambu, 2000.

ACSELRAD, .H. As práticas espaciais e o campo dos conflitos ambientais. In: ACSELRAD, H.. Conflitos Ambientais no Brasil. Rio de Janeiro: Fundação Heinrich Böll, 2004.

ALBRECHTS, L.. Strategic (spatial) planningreexamined. Environment and Planning B: Planning and Design, London, v.31, 2004, DOI: https://doi.org/10.1068/b3065

BECKER, B. K.; EGLER, C. A.. Detalhamento da Metodologia para Execução do Zoneamento Ecológico-Econômico pelos Estados da Amazônia Legal. Brasília: MMA, 1996.

BRASIL. Lei Federal no 6.938. Política Nacional de Meio Ambiente (PNMA). Brasília: DOU, 1981.

BRASIL. Constituição da República Federativa do Brasil de 1988. Brasília: DOU, 1988.

BRASIL. Decreto Federal $\mathbf{n}^{\circ}$ 4.297. Estabelece critérios para o Zoneamento Ecológico-Econômico do Brasil - ZEE. Brasília: DOU, 2002.

BRASIL. Lei Federal no 12.651. Dispõe sobre a proteção da vegetação nativa. Brasília: DOU, 2012.

BRASIL. Ministério do Meio Ambiente. Diretrizes Metodológicas para o Zoneamento Ecológico-Econômico do Brasil. 3 ed. Brasília: MMA, 2006.

BRASIL. Ministério do Meio Ambiente. Programa Zoneamento Ecológico-Econômico do Brasil. Brasília: MMA, 2011.

CHAVES, M. P. S.; BARROS, J. F.; FABRÉ, N. N.. Conflitos Socioambientais e Identidades Políticas na Amazônia. Revista de Ciência Política, n.37, 2008.

COSTA, W. M.. O Estado e as políticas territoriais no Brasil. São Paulo: Contexto, 1988.

FERRÃO, J.. O Ordenamento do Território como Política Pública. Lisboa: Fundação Calouste Gulbenkian, 2011.

FIGUEIREDO, A. H.. Visão Governamental. In: MINISTÉRIO DA INTEGRAÇÃO NACIONAL. PARA PENSAR UMA POLÍTICA NACIONAL DE ORDENAMENTO TERRITORIAL. Anais. Brasília,
2005. p.63.

GASPAR, J.. O Novo Ordenamento do Território: Geografia e Valores. Lisboa: Scripta Vetera, 1995.

MORAES, A. C. R. Ordenamento territorial: uma conceituação para o planejamento estratégico. In: MORAES, A. C. R.. Meio ambiente e ciências humanas. 4 ed. São Paulo: Annablume, 2005. p.139-149.

PERES, R. B.; CHIQUITO, E. A.. Ordenamento Territorial, Meio Ambiente e Desenvolvimento Regional: Novas Questões, Possíveis Articulações. Revista Brasileira de Estudos Urbanos e Regionais, v.14, n.2, p.71-86, 2012. DOI: http://dx.doi.org/10.22296/2317-1529.2012v14n2p71

RAFFESTIN, C.. Por uma geografia do poder. São Paulo: Ática, 1993

RIO DE JANEIRO. Secretaria de Estado do Ambiente (SEA). Benchmarking Internacional. Elaboração do Zoneamento Ecológico Econômico do Estado do Rio de Janeiro. Rio de Janeiro: SEA, 2015

RIO DE JANEIRO. Instituto Estadual do Ambiente (INEA). Diagnóstico do Setor Costeiro da Baía da Ilha Grande: Subsídios a Elaboração do Zoneamento Ecológico-Econômico Costeiro. Rio de Janeiro: INEA, 2015.

RODRIGUEZ, J. M. M.; SILVA, E. V.. Planejamento e gestão ambiental: subsídios da geoecologia das paisagens e da teoria geossistêmica. Rio de Janeiro: UFC, 2013

RÜCKERT, A. A.. O Processo de Reforma do Estado e a Política Nacional de Ordenamento Territorial. In: MINISTÉRIO DA INTEGRAÇÃO NACIONAL. PARA PENSAR UMA POLÍTICA NACIONAL DE ORDENAMENTO TERRITORIAL. Anais. Brasília, 2005. p.31-39.

SOUZA, C.. Políticas Públicas: Uma Revisão da Literatura. Sociologias, Porto Alegre, v.8, n.16, 2006, p.20-45. DOI: https://doi.org/10.1590/s1517-45222006000200003

SOUZA, M. J. L.. O território: sobre espaço e poder, autonomia e desenvolvimento. In: CASTRO, I. E.; GOMES, P. C. C.; CORRÊA, R. L.. Geografia: conceitos e temas. Rio de Janeiro: Bertrand Brasil, 2000. p.77-116.

TRICART, J.. Ecodinâmica. Rio de Janeiro: IBGE, Diretoria Técnica, SUPREN, 1977.

A CBPC - Companhia Brasileira de Produção Científica (CNPJ: 11.221.422/0001-03) detém os direitos materiais desta publicação. Os direitos referem-se à publicação do trabalho em qualquer parte do mundo, incluindo os direitos às renovações, expansões e disseminações da contribuição, bem como outros direitos subsidiários. Todos os trabalhos publicados eletronicamente poderão posteriormente ser publicados em coletâneas impressas sob coordenação da Sustenere Publishing, da Companhia Brasileira de Produção Científica e seus parceiros autorizados. Os (as) autores (as) preservam os direitos autorais, mas não têm permissão para a publicação da contribuição em outro meio, impresso ou digital, em português ou em tradução. 